\title{
Analysis of Surface Characteristics for Al-SiC Metal Matrix Composites Machined by Wire Electrical Discharge Machining (WEDM)
}

\author{
Jaspreet Singh ${ }^{1, *}$ and Sanjeev Saini ${ }^{2}$ \\ ${ }^{1}$ Research Scholar, Department of Mechanical Engineering, Ph.D. Scholar, I.K.G. \\ Punjab Technical University, Kapurthalla, Punjab, India \\ 2Department of Mechanical Engineering, DAVIET, Jalandhar, Punjab, \\ Jalandhar-144011, India
}

\begin{abstract}
Article Type: Article
Article Citation: Jaspreet Singh, Sanjeev Saini. Analysis of surface characteristics for Al-SiC metal matrix composites machined by wire electrical discharge machining (WEDM). Indian Journal of Science and Technology. 2020; 13(09),1027-1034.001:10.17485/ijs/2020/ v013i09/148091
\end{abstract}

Received date: 0 ctober 11, 2019

Accepted date: January 29, 2020

*Author for correspondence: Jaspreet Singh \jassi21387@ gmail.com 9 I.K.G. Punjab Technical University, Kapurthalla, Punjab, India

\section{Abstract}

Objectives: The application of light weight products used for automobile needs to require the use of Al metal matrix composites (MMCs). The optimized combination of process variables has been found to accomplish for better machining. Methods/statistical analysis: There is different type of machining methods used for machining of MMC but it is not so easy to machine these materials with full efficiency and desired output responses because of difficult to machine these materials as compared to other unreinforced materials like alloys and smart materials. The main reason behind hardness of aluminum MMCs is heterogeneous structure which makes its surface layer with high fatigue strength, smooth, and tough. $L_{9}$ orthogonal array has been used to perform the experiments. Findings: The effect of parameters has been calculated and analyzed for response analysis. The effect of various machining parameters like wire diameter, current, voltage, pulse on time, and pulse off time is observed and analyzed on surface properties of the $\mathrm{Al}-\mathrm{SiC}$ MMCs. As a result of compressive residual stress on the surface that is a plus point for material to use it for tough work, but along with this it will cause high tool wear and surface imperfections while machining, so these are some reasons for the recommendation of non-conventional machining methods to machine aluminum matrix composites. So, several new techniques were added in some past few years of research which is explained in this research article. Application/improvements: Wire electrical discharge machining (WEDM) which is an advanced machining method which is used for manufacture difficult shapes conductive work piece materials. Experimental work will be done on the WEDM of AI-SiC MMC.

Keywords: Aluminium Metal Matrix Composite Al-SiC, Surface Roughness, Wire Electrical Discharge Machining (WEDM), Surface Integrity, Taguchi's Method, Response and Regression Analysis. 


\section{Introduction}

Now a day's Nano-metal matrix composite (MMC) as one of the advanced MMCs made with an aluminum matrix with enforcements of silicon carbide $(\mathrm{SiC})$, Graphene, Titanium boride $\left(\mathrm{TiB}_{2}\right)$, and titanium carbide $(\mathrm{TiC})$ particles [1]. It has been confirmed that materials with high toughness and hardness can be machined by using typical cemented carbide tools, but for machining of materials like aluminum MMC reinforced with SiC were far more difficult to machine on conventional machining due to their more abrasive nature [2-3]. Surface integrity is one of the significant factors to be measured while machining MMCs [4]. In addition to this microstructure of the outer layer is repeatedly damaged due to the contact of MMCs cutting edges of conventional tooling and for insight tool wear which will quickly become damaged, and rounded [5-6]. The diamond tool is good cutter instead of conventional cemented carbide tool because it preserves a sharp cutting edge and it has been capable for cutting the soft reinforced work material like $\mathrm{Al}_{2} \mathrm{O}_{3}$ fibers, etc [7] So several new techniques were added in some past few years of research out of which wire EDM is a non-conventional method of machining. Aluminum metal matrix Composite materials gives improved mechanical properties which will depend on the constituents and percentage of constituents added in the material [8-9]. Silicon carbide ( $\mathrm{SiC}$ ), Graphene, Titanium boride $\left(\mathrm{TiB}_{2}\right)$, and titanium carbide $(\mathrm{TiC})$ particles are reinforcing elements. In the present study, WEDM of $\mathrm{Al}-\mathrm{SiC}$ composites with varying percentage of silicon carbide $(\mathrm{SiC})$ as for $5 \%, 10 \%$, and $15 \%$ volume proportion. Various machining parameters like wire diameter, servo voltage, current, pulse-on time, and pulse-off time [10-11]. Desired performance characteristics after experiments in this exploration are mainly material removal rate and surface roughness [12]. Taguchi design of experimental method has been used for developing the experimental runs for experimentation. For best results, an $\mathrm{L}_{9}$ orthogonal array has been assumed to conduct the experiments on all the three work pieces [13-14]. To produce a relationship between the selected inputs and outputs characteristics, multiple regression analysis has been performed and found optimized values of current, servo voltage, pulse-on time and pulse-off and significant result values of surface roughness and material removal rate. Aluminum MMCs exist one of the significant types of MMC because of their advanced properties like utmost strength and very light weight. Development of all these lightweight materials has on condition that the automotive industry with several potentials for vehicle weight reduction [15].

The application of wire electric discharge machining (WEDM) offers high surface finish without changing physical properties for the components.

\section{Materials and Method}

The material used in the present investigation was an aluminum MMC composition of material was tested by chemical analysis on D.R. Spectrometer of polywac 2000. Chemical compositions of pure aluminum. The process parameters used and levels used for WEDM include control panel, machine chamber, Wire feed system. Al-SiC was selected as work piece material. The MMC was prepared by using stir die casting method. All the experiments 
have been conducted on wire EDM (Model: MIC: 432CS). Brass wire as electrode is used with continuous feed rate and connected among the rollers for continuous supply. The $\mathrm{L}_{9}$ orthogonal array was selected for conducting the experiments. The dielectric fluid used for the experiments is deionized water. The results after experimentation were analyzed by the analysis of variance (ANOVA) as shown in Tables 1-3.

TABLE 1. Range used for the experimentation of parameters

\begin{tabular}{llrrr}
\hline Parameters used & Range of parameters & \multicolumn{3}{c}{ Level } \\
\cline { 3 - 5 } & & $\mathbf{1}$ & $\mathbf{2}$ & \multicolumn{1}{c}{$\mathbf{3}$} \\
\hline Current A & $0-25 \mathrm{~A}$ & 10 & 15 & 20 \\
Pulse-on time $(\mu \mathrm{s})$ & $0.5-2000 \mu \mathrm{s}$ & 150 & 300 & 450 \\
Pulse-off time $(\mu \mathrm{s})$ & $1-9$ & 50 & 70 & 90 \\
Servo voltage V & $0-50 \mathrm{~V}$ & 15 & 20 & 25 \\
\hline
\end{tabular}

TABLE 2. Chemical compositions of pure aluminum (wt.\%)

\begin{tabular}{lcccccccc}
\hline Al & Si & $\mathbf{C u}$ & Mn & Fe & Ni & Sn & Zn & Pb \\
\hline 99.8 & 0.2 & 0.02 & 0.02 & 0.04 & 0.02 & 0.003 & 0.01 & 0.004 \\
\hline
\end{tabular}

TABLE 3. Chemical compositions of used aluminum metal matrix composite

\begin{tabular}{lcc}
\hline Material name & Al & Average particle size SiC $\mathbf{8 0} \boldsymbol{\mu m})$ \\
\hline L 1 & $93.9 \%$ & $5-7 \%$ \\
L 3 & $86.9 \%$ & $10-12 \%$ \\
L 4 & $82.9 \%$ & $15-18 \%$ \\
\hline
\end{tabular}

\section{Results and Discussions}

ANOVA is used to identify the exact optimized results; hence in this experimental study the significant factors which will affect the performance of WEDM are measured. To find out results for MRR, the confidence interval of $95 \%$ is used which will give variable data shown in Table 4 to find out the values of $F$ by calculating the formula $F=$ MS for the term/

TABLE 4. $L_{9}$ orthogonal array matrix used in experimentation

\begin{tabular}{lccc}
\hline S. No. & Peak current (ampere) & Pulse-on time & Pulse-off time \\
\hline 1 & 10 & 150 & 5 \\
2 & 10 & 300 & 7 \\
3 & 10 & 450 & 9 \\
4 & 15 & 300 & 9 \\
5 & 15 & 150 & 7 \\
6 & 15 & 450 & 5 \\
7 & 20 & 150 & 9 \\
8 & 20 & 300 & 5 \\
9 & 20 & 450 & 7 \\
\hline
\end{tabular}


Ms for the error term after finding the $F$ tested values they gives out significant results. $F$ test will recognize the particular parameter which is actually affecting the machining process and gives the significant factor out of used four factors. As the value of $F$ is greater, the greater is the influence of that particular parameter on machining.

MRR is calculated from the given formula:

MRR is calculated by $=$ Diff. in weight of work piece before and after machining/Time of machining

$W_{i}=$ Initial weight $(\mathrm{gm}), W_{f}=$ Final weight $(\mathrm{gm}), \mathrm{t}=$ Time period

\subsection{Regression Model for MRR}

After finding experimental results and $F$ values of different parameters at $95 \%$ of confidence interval, Table 5 shows that current ( $F 6.89$ value), pulse on time ( $F 3.75$ value), and pulse off is 1.01 which are affecting values of the machining parameters out of them $F$ value of current which is 6.89 is much more as compared to other two parameters so according to results, current is one of the significant factor.

By using Minitab 19, the regression equation is made for the MRR and then the interaction plot is made between averages of signal to noise ratio of the different parameters and output parameter as MRR of material by analyzing these plots it has been studied that current is one of the parameters which have the highest contribution to MRR, as we increase the value of discharge current the value of MRR increases, but simultaneously there is an effect of pulse on and pulse off time is also considerable.

Equation 1: Regression Equation of MRR for material

MRR $=0.578+0.2284$ Peak Current (ampere) +0.0529 Pulse-on Time $(\mu s)-0.02975$ Pulse-off time $(\mu \mathrm{s})$

TABLE 5. ANOVA table of $S N$ ratios for $M R R$

\begin{tabular}{lcccccc}
\hline \multicolumn{1}{c}{ Parameter } & DF & Seq SS & Adj SS & Adj MS & $\boldsymbol{F}$ & $\boldsymbol{P}$ \\
\hline Peak current (ampere) & 2 & 48.037 & 48.037 & 24.018 & 6.89 & 0.127 \\
Pulse-on time $(\mu \mathrm{s})$ & 2 & 26.145 & 26.145 & 13.072 & 3.75 & 0.210 \\
Pulse-off time $(\mu \mathrm{s})$ & 2 & 7.012 & 7.012 & 3.506 & 1.01 & 0.499 \\
Residual error & 2 & 6.970 & 6.970 & 3.485 & & \\
Total & 8 & 88.163 & & & & \\
\hline
\end{tabular}

\subsection{Model Summary}

\begin{tabular}{ccc}
\hline $\mathbf{S}$ & $\mathbf{R}-\mathbf{S q}$ & $\mathbf{R}-\mathbf{S q}$ (adj) \\
0.6027 & $95.07 \%$ & $80.29 \%$ \\
\hline
\end{tabular}

\subsection{Regression Model for SR}

After the experiments, the values of $\mathrm{Ra}$ are found and analyzed by using ANOVA by considering the confidence interval at $95 \%$ which is given in Table 6 also by considering 
TABLE 6. ANOVA table for SN ratios of surface roughness

\begin{tabular}{lcrrrrc}
\hline Parameters & DF & Seq SS & Adj SS & Adj MS & \multicolumn{1}{c}{$\boldsymbol{F}$} & $\boldsymbol{P}$ \\
\hline Peak current (ampere) & 2 & 112.164 & 112.164 & 56.082 & 20.64 & 0.046 \\
Pulse-on time $(\mu \mathrm{s})$ & 2 & 3.629 & 3.629 & 1.815 & 0.67 & 0.600 \\
Pulse-off time $(\mu \mathrm{s})$ & 2 & 21.261 & 21.261 & 10.631 & 3.91 & 0.204 \\
Residual error & 2 & 5.433 & 5.433 & 2.717 & & \\
Total & 8 & 142.488 & & & & \\
\hline
\end{tabular}

the values of surface roughness as smaller is better the $F$ values were found for different parameters as for discharge current it is 20.64 , for pulse on time it is 0.67 , and for pulseoff time $F$ value is 3.91. They were found to be significant in surface interactions studied during trials were found to be significant for surface roughness. As a result, discharge current has the highest contribution to surface roughness.

The regression equation (2) of surface roughness is given below for the analysis of results.

Equation 2: Regression Equation of surface roughness for material

$\mathrm{Ra}=-2.28+0.3336$ Peak Current (ampere) +0.0174 Pulse-on Time $(\mu \mathrm{s})+0.0049$ Pulse-off time ( $\mu$ s)

\subsection{Model Summary}

\begin{tabular}{ccc}
\hline $\mathbf{S}$ & $\mathbf{R}-\mathbf{S q}$ & $\mathbf{R}-\mathbf{S q}$ (adj) \\
\hline 0.2424 & $99.44 \%$ & $97.76 \%$ \\
\hline
\end{tabular}

Current is one of the parameters which have the highest influence to increase or decrease the surface roughness. Desired performance measures of surface roughness for material interaction plot are shown in Figures 1-4.

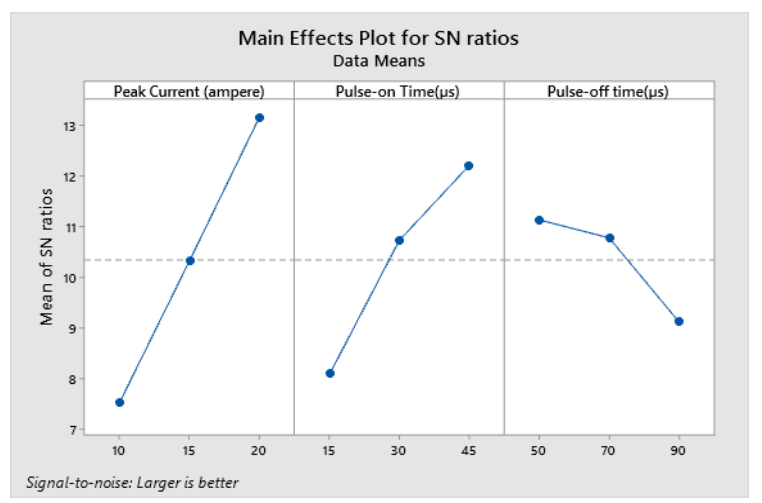

FIGURE 1. Main effect plots for S/N ratio of MRR for material. 


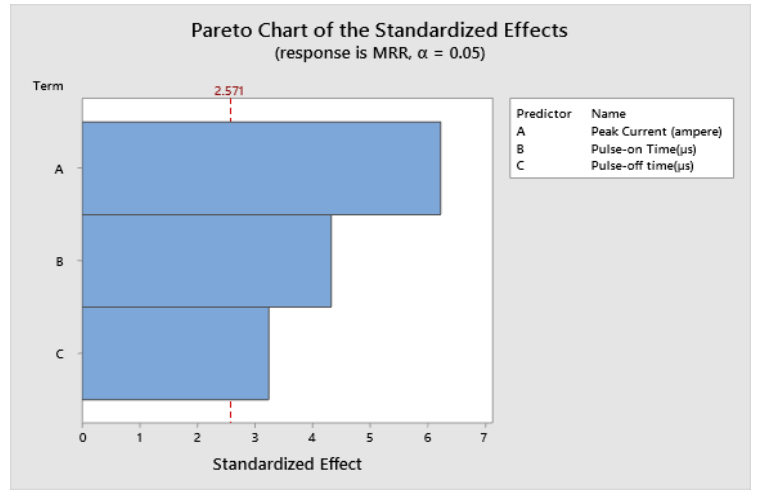

FIGURE 2. Desired performance measures of MRR for material.

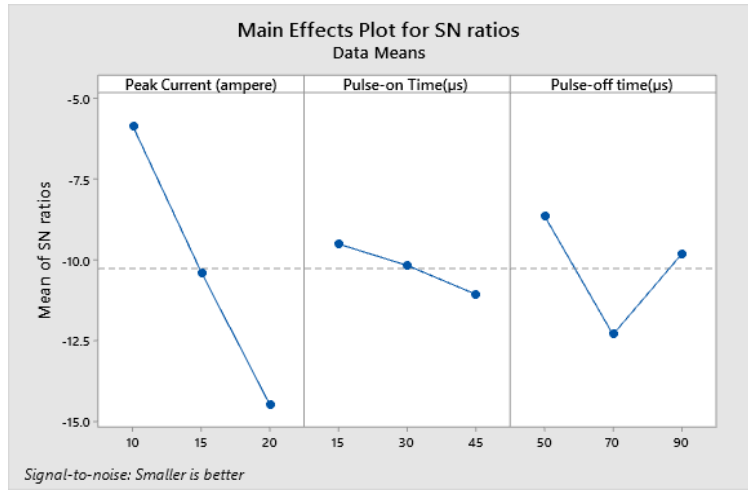

FIGURE 3. Main effect plots for $\mathrm{S} / \mathrm{N}$ ratio of surface roughness for material.

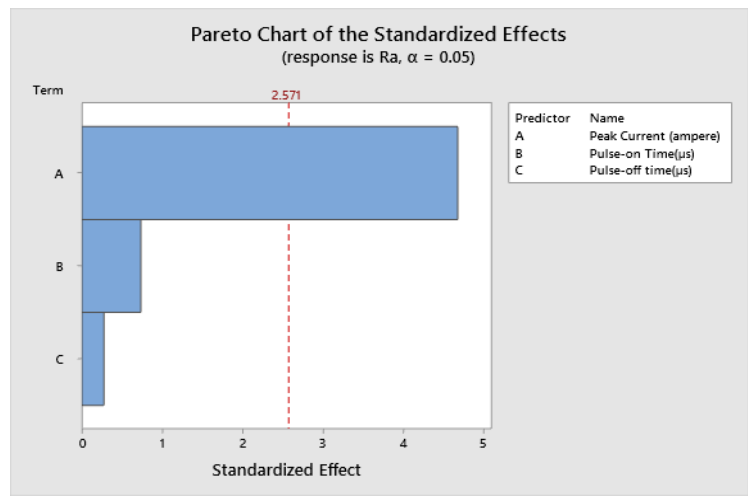

FIGURE 4. Desired performance measures of surface roughness for material.

\section{Conclusions}

The experimental study reveals the optimized results after using optimization techniques; the modeling and analysis are done by Minitab 19. After the analysis, the following conclusions are attained. 
- In this experimental study, some outcomes after machining with WEDM having process variables like MRR and SR of aluminum MMC are investigated.

- Here discharge current is most significant factor after the analysis at $95 \%$ confidence interval, MRR and SR are having percentage contribution of $65.33 \%, 47.43 \%$, respectively.

\section{Acknowledgement}

The authors gratefully acknowledge the technical support provided by IKG Punjab Technical University, Kapurthala, India for carrying out this work.

\section{References}

1. Bamberg E, Rakwal D. Experimental investigation of wire electrical discharge machining of gallium-doped germanium. Journal of Materials Processing Technology. 2008, 197(1-3), 419427. https://doi.org/10.1016/j.jmatprotec.2007.06.038

2. Mohri N, Fukuzawa Y, Tani T. Some considerations to machining characteristics of insulating ceramics towards practical use in industry. CIRP Annals. 2002, 51(1), 112-116. https://doi. org/10.1016/S0007-8506(07)61490-5

3. Yeo S, Yap G. A feasibility study on the micro electro-discharge machining process for photomask fabrication. International Journal of Advanced Manufacturing Technology. 2001, 18, 7-11. https://link.springer.com/article/10.1007/PL00003950

4. Ho K, Newman S. State of the art in wire electrical discharge machining (WEDM). International Journal of Machine Tools and Manufacture. 2004, 44(1-2), 1247-1259. https://doi.org/10.1016/j. ijmachtools.2004.04.017

5. Qu J, Shih A, Scattergood R. Development of the cylindrical wire electrical discharge machining process. Part 1.concept, design, and material removal rate. Transactions of ASME. 2002, 124, 702-707. https://doi.org/10.1115/1.1475321

6. Garg R, Singh K, Sachdeva A, Sharma V, Ojha K, Singh S. Review of research work in sinking EDM and WEDM on metal matrix composite materials. International Journal of Advanced Manufacturing Technology. 2010; 50(5-8), 611-624. https://link.springer.com/article/10.1007/ s00170-010-2534-5

7. Mathew B, Benkim B, Babu J. Multiple process parameters optimization of WEDM on AISI304 using utility approach. Procedia Materials Science. 2014, 5, 1863-1872. DOI: 10.1016/j. mspro.2014.07.349.

8. Goswami A, Kumar J. Optimization in wire-cut EDM of Nimonic-80A using Taguchi's approach and utility concept. Engineering Science and Technology an International Journal. 2014, 17(4), 236-246. https://doi.org/10.1016/j.jestch.2014.07.001

9. Saedon J, Jaafar N, Yahaya M, Saad N, Kasim M. Multi-objective optimization of titanium alloy through orthogonal array and grey relational analysis in WEDM. Procedia Technology. 2014, 15, 833-841. https://doi.org/10.1016/j.protcy.2014.09.057

10. Manjaiah M, Narendranath S, Javad A. Optimisation of wire electro discharge machining parameters to achieve better MRR and surface finish. Procedia Materials Science. 2014, 5, 26352644. https://doi.org/10.1016/j.mspro.2014.07.525 
11. Gowd G, Reddy M, Sreenivasulu B, Ravuri M. Multi objective optimisation of process parameters in WEDM during machining of SS304. Procedia Materials Science. 2014, 5, 1408-1416. https:// doi.org/10.1016/j.mspro.2014.07.459

12. Han F, Jiang J, Yu D. Influence of machining parameters on surface roughness in finish cut of WEDM. International Journal of Advanced Manufacturing Technology. 2007, 34, 538-546. https://link.springer.com/article/10.1007/s00170-006-0629-9

13. Pujari S, Koona R, Satyanarayan B. Experimental investigation and optimisation of wire EDM parameters for surface roughness, MRR and white layer in machining of aluminium alloy. Procedia Materials Science. 2014, 5, 2197-2206. https://doi.org/10.1016/j.mspro.2014.07.426

14. Raju P, Sarcar M, Satyanarayana B. Optimisation of wire electric discharge machining parameters for surface roughness on 316L stainless steel using full factorial experimental design. Procedia Materials Science. 2014, 5, 1670-1676. https://doi.org/10.1016/j.mspro.2014.07.355

15. Mohan B, Rajadurai A, Satyanarayana KG. Electric discharge machining of Al-SiC metal matrix composites using rotary tube electrode. Journal of Materials Processing Technology. 2004, 153-154, 978-985. DOI: 10.1016/j.jmatprotec.2004.04.347.

16. Kandpal BC, Kumar J, Hari Singh. Machining of aluminium metal matrix composites with electrical discharge machining - a review. Materials Today: Proceedings. 2015, 2(4-5), 16651671. https://doi.org/10.1016/j.matpr.2015.07.094 